\title{
Vertical Transmission Rate of HIV from Seropositive Mothers Followed in the Different Care Centers in Kinshasa from 2010 to 2015
}

\section{Divine Chuga ${ }^{*}$, Ben Ilunga Bulanda ${ }^{1}$, Jean Yves Debels Kabasele ${ }^{1}$, Médard Omakoy Okonda ${ }^{1}$, Berry Ikolango Bongenya ${ }^{1}$, Erick Ntambwe Kamangu ${ }^{1,2 *}$}

\author{
${ }^{1}$ Research Group "Focus on HIV/AIDS”, Kinshasa, Democratic Republic of Congo \\ ${ }^{2}$ Molecular Biochemistry Service, Department of Basic Sciences, Faculty of Medicine, University of Kinshasa (UNIKIN), \\ Kinshasa, Democratic Republic of Congo \\ Email: *erick.kamangu@unikin.ac.cd, ^divine.chuga@gmail.com
}

How to cite this paper: Chuga, D., Bulanda, B.I., Kabasele, J.Y.D., Okonda, M.O., Bongenya, B.I. and Kamangu, E.N. (2018) Vertical Transmission Rate of HIV from Seropositive Mothers Followed in the Different Care Centers in Kinshasa from 2010 to 2015. Open Access Library Journal, 5: e4769.

https://doi.org/10.4236/oalib.1104769

Received: July 11, 2018

Accepted: August 11, 2018

Published: August 14, 2018

Copyright ( 2018 by authors and Open Access Library Inc.

This work is licensed under the Creative Commons Attribution International License (CC BY 4.0).

http://creativecommons.org/licenses/by/4.0/

\section{(c) (i) Open Access}

\begin{abstract}
Background: In the Democratic Republic of Congo, the use of Prevention of Transmission of Human Immunodeficiency Virus infection from mother to child is still very low. Objective: The objective of this study was to estimate the prevalence of infants born from HIV-positive mother in different centers in Kinshasa. Methods: This study is a retrospective cohort of at least 2 years on the records of mother-child couple followed in 8 centers of Kinshasa. Based on a sample survey form with specific criteria, some files were selected. Results: The record keeping of all centers was estimated at $70 \%$ on average; the most represented age group was from 26 to 35 years with 102 women (54\%) out of 190. Forty-five percent (45\%) of pregnant women started pre-natal consultation (CPN) in the 2nd trimester of pregnancy. All mothers had been diagnosed with 3 Rapid Diagnostic Tests (RDT). The majority of women were under: AZT + 3TC + NVP and CTX and 139 (73\%) women were diagnosed at stage 1 of HIV infection according to WHO's standard. One hundred new born were male. Seventy-eight newborns weighed between 2.01 and $3.00 \mathrm{~kg}$ at birth. Ninety seven percent of newborns were treated at birth. Ninety-one children who were on Nevirapine syrup; six of them were not put on treatment. Ninety five percent of newborns were diagnosed HIV-negative 9 months after birth by PCR; 2\% of children were undiagnosed as a result of refusal and $3 \%$ of children had undetermined serology. This gives a mother-to-child transmission rate of $2 \%$ at 9 months of birth for the centers of Kinshasa. Conclusion: Despite the insufficient coverage of the PMTCT service in our community, the centers in Kinshasa respond to the PMTCT approach and the transmission rate in the 8 centers of 4 districts of
\end{abstract}


Kinshasa is $2 \%$.

\section{Subject Areas}

Public Health

\section{Keywords}

PMTCT, Mother, Child, HIV, Kinshasa

\section{Introduction}

Acquired Immune Deficiency Syndrome (AIDS) is a condition that causes a fall in the natural immune defenses caused by the Human Immunodeficiency Virus (HIV). Since 1981, HIV and AIDS have been a major public health problem in the world, particularly in sub-Saharan Africa [1]. In the Democratic Republic of Congo (DRC), the average prevalence was 1.2\% for HIV infection in 2013 [2]. Although the response to HIV infection and AIDS is winning globally, the number of new infections has dropped by $17 \%$ in eight years [3]. However, optimism remains measured since it counts every day in the world 7400 new infections, including 1200 cases in children [3]. The decline in the vertical transmission of HIV is increasing worldwide through the work of the organizations involved in the response to HIV infection in the newborn and the HIV-positive mother. In the DRC, this response is not yet satisfactory [4].

According to the World Health Organization (WHO) in its protocol on PMTCT the adoption of a single scheme (option A) for ART in pregnant women would not be enough. The arrival of the third, option $\mathrm{B}+$, would strengthen links to achieve a better result [5]. In the DRC this option was adopted in 2012 [6]. Estimating this prevalence is possible only by looking at HIV-positive mothers and basing themselves on knowledge of key indicators such as the period of treatment of HIV-positive pregnant women and the choice of type breastfeeding which will influence mother-to-child transmission of HIV [7]. This study aims to evaluate PMTCT and to estimate the prevalence of mother-to-child transmission of HIV infection in different centers in Kinshasa.

\section{Methods}

The present study is a 2-year retrospective cohort based on the records of motherchild pairs in 8 different centers in Kinshasa. It was composed of 309 files, of which 190 mother-child pairs were selected.

Based on a modeled survey form and on very specific criteria: 1) monitoring centers with a maternity unit organizing and offering PMTCT services for at least 2 years; 2) records of any patient up to 18 years of age, diagnosed HIV-positive at the follow-up center confirmed by at least 2 Rapid Diagnostic Tests (RDT-Determines, Unigold, and/or Double Check); with confirmation 
with a 3rd RDT in case of doubt according to WHO recommendation [4]; 3) women having given birth in this follow-up center; 4) women who have attended pre-natal consultation (CPN) in this specific center; 5) records containing all anthropometric and socio-demographic data. The important information had been collected from the records of the mother-child couple on different items of interest; regarding mothers: 1) their age, 2) the age of pregnancy at the beginning of prenatal consultation, 3) the date of HIV testing, 4) the method of diagnosis, 5) the clinical stage at start, 6) the type of treatment regimen and 7) the treatment start date were selected as parameters of interest for the mother. For newborns: 1) date of birth, 2) gender, 3) weight, 4) height, 5) therapeutic regimen at birth, 6) date of screening, and 7) the diagnostic method were used as the parameter of interest for newborns.

\section{Results}

The record keeping in all the centers was estimated at $70 \%$ on average. It was estimated at $100 \%$ for the Maternity of Kintambo, $92 \%$ for the Mother and Child Center of Bumbu (MCCB), 82\% for the Saint Gabriel Center, 79\% for Pilot Maternity of Masina, 71\% for the Mother and Child Center of Ngaba (MCCN), 67\% for the Emerald Center, $41 \%$ for the Kasa-Vubu Trinity Center and 29\% for the Binza Maternity Center. Of the 190 selected cases of HIV-positive pregnant women, the most represented age group was that of 26 to 35 years with 102 mothers (54\%), followed by those of 36 to 45 with 58 mothers (31\%), as shown in Table 1.

Sixteen mothers (8\%) started Prenatal Consultation (PNC) in the first trimester of pregnancy, 88 mothers (45\%) started PNC in the second trimester of pregnancy and 50 mothers (26\%) in the third trimester of pregnancy. All mothers were diagnosed with the 3 RDT according to the national program recommendations. One hundred and thirty-nine mothers (73\%) were diagnosed at stage 1 of HIV infection, 45 mothers (24\%) diagnosed at stage 2 and 6 mothers (3\%) had been diagnosed at stage 3. All mothers were on first-line anti-retroviral drugs (ARVs). The majority of women (71\%) were on AZT + 3TC + NVP plus cotrimoxazole (CTX), 13\% of women on TDF + 3TC + EVP, $8 \%$ on AZT + CTX, $3 \%$ on $\mathrm{AZT}+\mathrm{EFV}, 0.5 \%$ on $\mathrm{AZT}+\mathrm{FN}$ and $\mathrm{AZT}+\mathrm{L}$ each, $0.5 \%$ under $\mathrm{B}+$ and $0.5 \%$ had refused treatment.

For the newborns, the male gender was the most represented, with 100 boys (52\%) compared to $48 \%$ girls, while at birth 78 newborns (41\%) weighed between 2.01 and $3.00 \mathrm{~kg}$ weight, followed by those weighing between 3.01 and $4.00 \mathrm{~kg}(34 \%), 2 \%$ weighed between 1.00 and $2.00 \mathrm{~kg}$ and those weighing more than $4.00 \mathrm{~kg}$ were $3(2 \%)$. One hundred eighty five newborns (97\%) were being treated at birth, $49 \%$ were on Nevirapine syrup, $45 \%$ had Nevirapine syrup and CTX, and 6\% under CTX only. Six children were not put on treatment. Ninety five percent of newborns born from HIV-positive mothers were diagnosed HIV negative 9 months after birth by PCR, 2\% of newborns were undiagnosed as a 
Table 1. Sociodemographic data of mothers included in the study.

\begin{tabular}{|c|c|c|c|c|c|c|c|c|c|c|c|c|c|}
\hline \multirow{3}{*}{ Characteristics } & \multicolumn{12}{|c|}{ Districts } & \multirow{3}{*}{ Total } \\
\hline & \multicolumn{3}{|c|}{ Funa } & \multicolumn{3}{|c|}{ Lukunga } & \multicolumn{3}{|c|}{ Mont Amba } & \multicolumn{3}{|c|}{ Tshangu } & \\
\hline & KTC & $\mathrm{MCCB}$ & Sub-Total & $\begin{array}{l}\text { Maternity } \\
\text { of Binza }\end{array}$ & $\begin{array}{l}\text { Maternity } \\
\text { of } \\
\text { Kintambo }\end{array}$ & Sub-Total & $\begin{array}{c}\text { St } \\
\text { Gabriel }\end{array}$ & $\mathrm{MCCN}$ & Sub-Total & merald & $\mathrm{PMM}$ & Sub-Total & \\
\hline \multicolumn{14}{|c|}{ Groups of age (years) } \\
\hline $18-25$ & 2 & 1 & 3 & 2 & 5 & 7 & 6 & 0 & 6 & - & - & - & 16 \\
\hline $26-35$ & 8 & 40 & 48 & 21 & 19 & 40 & 10 & 4 & 14 & - & - & - & 102 \\
\hline $36-45$ & 1 & 27 & 28 & 13 & 14 & 27 & 2 & 1 & 3 & - & - & - & 58 \\
\hline Over 45 & 0 & 1 & 1 & 0 & 0 & 0 & 0 & 0 & 0 & - & - & - & 1 \\
\hline \multicolumn{14}{|c|}{ 1st Prenatal consultation } \\
\hline 1st trimester & 1 & 3 & 4 & -- & 6 & 6 & 0 & 0 & 0 & 1 & 5 & 6 & 16 \\
\hline 2nd trimester & 6 & 47 & 53 & -- & 19 & 19 & 8 & 3 & 11 & 0 & 5 & 5 & 88 \\
\hline 3rd trimester & 4 & 19 & 23 & -- & 13 & 13 & 10 & 2 & 12 & 1 & 1 & 2 & 50 \\
\hline \multicolumn{14}{|c|}{ Methods of diagnosis (RDT) } \\
\hline Determine & 11 & 69 & 80 & 36 & 38 & 74 & 18 & 5 & 23 & 2 & 11 & 13 & 190 \\
\hline Unigold & 11 & 69 & 80 & 36 & 38 & 74 & 18 & 5 & 23 & 1 & 11 & 12 & 189 \\
\hline Double check & 0 & 69 & 69 & 36 & 38 & 74 & 18 & 0 & 18 & 0 & 0 & 0 & 161 \\
\hline \multicolumn{14}{|c|}{ Clinical stage according to WHO's recommendations } \\
\hline Stage 1 & 4 & 67 & 71 & 27 & 19 & 46 & 17 & 3 & 20 & 2 & 0 & 2 & 139 \\
\hline Stage 2 & 6 & 2 & 8 & 6 & 19 & 25 & 0 & 1 & 1 & 0 & 11 & 11 & 45 \\
\hline Stage 3 & 1 & 0 & 1 & 3 & 0 & 3 & 1 & 1 & 2 & 0 & 0 & 0 & 6 \\
\hline Stage 4 & 0 & 0 & 0 & 0 & 0 & 0 & 0 & 0 & 0 & 0 & 0 & 0 & 0 \\
\hline \multicolumn{14}{|c|}{ Type of ARV used } \\
\hline $\begin{array}{c}\mathrm{AZT}+3 \mathrm{TC}+ \\
\mathrm{NVP}+\mathrm{CTX}\end{array}$ & 8 & 57 & 65 & 27 & 18 & 45 & 14 & 1 & 15 & 0 & 10 & 10 & 135 \\
\hline $\begin{array}{c}\mathrm{TDF}+3 \mathrm{TC}+ \\
\mathrm{EFV}\end{array}$ & 0 & 12 & 12 & 1 & 5 & 6 & 0 & 4 & 4 & 2 & 0 & 2 & 24 \\
\hline CTX & 3 & 0 & 3 & 0 & 0 & 0 & 3 & 0 & 3 & 0 & 0 & 0 & 6 \\
\hline $\mathrm{AZT}+\mathrm{EFV}$ & 0 & 0 & 0 & 6 & 0 & 6 & 0 & 0 & 0 & 0 & 0 & 0 & 6 \\
\hline ZFN/1Z 3L & 0 & 0 & 0 & 2 & 0 & 2 & 0 & 0 & 0 & 0 & 0 & 0 & 2 \\
\hline $\mathrm{AZT}+\mathrm{CTX}$ & 0 & 0 & 0 & 0 & 15 & 15 & 0 & 0 & 0 & 0 & 0 & 0 & 15 \\
\hline $\mathrm{B}+$ & 0 & 0 & 0 & 0 & 0 & 0 & 1 & 0 & 1 & 0 & 0 & 0 & 1 \\
\hline None & 0 & 0 & 0 & 0 & 0 & 0 & 0 & 0 & 0 & 0 & 1 & 1 & 1 \\
\hline $\begin{array}{l}\text { Total per } \\
\text { Centers }\end{array}$ & 11 & 69 & 80 & 36 & 38 & 74 & 18 & 5 & 23 & 2 & 11 & 13 & 190 \\
\hline
\end{tabular}

KTC: Kasavubu Trinity Center, MCCB: Mother and Child Center of Bumbu, MCCN: Mother and Child Center of Ngaba, PMM: Pilote Maternity of Masina, AZT: Zidovudine, 3TC: Lamivudine, NVP: Nevirapine, CTX: Cotrimoxazole, TDF: Tenofovir, EFV: Efavirenz.

result of parental refusal and 3\% of newborns had indeterminate serology for HIV. 


\section{Discussion}

The objective of this study was to evaluate PMTCT and to estimate the prevalence of mother-to-child transmission of HIV infection in different centers in Kinshasa. Record keeping in all centers was estimated at $70 \%$ on average; $100 \%$ for the Maternity of Kintambo, 92\% for Mother and Child Center of Bumbu, $82 \%$ for Saint Gabriel center, 79\% for Pilot Maternity in Masina, 71\% for Mother and Child Center of Ngaba, $67 \%$ for the Emerald center, $41 \%$ for the Kasa-Vubu Trinity Center and 29\% for the Binza Maternity Center. This corroborates data from the literature reported in our community that states poor record keeping in the centers [8].

The most represented age group was of 26 to 35 years with 102 mothers (54\%). This could be explained by the fact that this age group is one that has a high sexual activity [7] and that the prevalence of HIV infection in women increases with age [2] [8] [9]. UNAIDS in its report adds that the age group with a high prevalence among pregnant women attending PNC over the world was of 25 to 49 years followed by that of 20 to 24 years [3]. The study by Kimbala and al. in Lubumbashi on HIV prevention from mother-to-child showed attendance of seropositive serrate women with the possibility of increasing the rate of PMTCT [10].

Sixteen mothers (8\%) attended the Prenatal Clinic (PNC) in the first trimester of pregnancy, 86 mothers (45\%) in the second trimester of pregnancy and 50 mothers $(26 \%)$ in the third trimester of pregnancy. While $45 \%$ of mothers presented to PNC in the 2nd trimester of pregnancy, national guidelines recommend the first PNC visit during the 1st trimester of pregnancy for better medical management of pregnancy, so that women benefit from the benefits associated with options to reduce Maternal-Fetal Transmission, as they need to be aware of their HIV status and accept it for proper management [7]. This corroborates the literature data reported by Mwemba et al. which states that all pregnant women do not correctly follow PNC sessions [11].

All mothers had been diagnosed with 2 or 3 RDT (190 with Determine, 189 with Unigold and 162 with Double Check) as recommended by national guidelines [6] [7]. One hundred and thirty-nine mothers (73\%) were diagnosed at stage 1 of HIV infection according to WHO's recommendations, 45 (24\%) were diagnosed at stage 2, and $6(3 \%)$ at stage 3 . All mothers were on first-line of ARVs. Seventy-one percent (71\%) were on AZT + 3TC + NVP plus CTX, 13\% of women on TDF + 3TC + EVP, $8 \%$ on AZT + CTX, $3 \%$ on AZT + EFV, $0.5 \%$ on $\mathrm{AZT}+\mathrm{FN}$ and $\mathrm{AZT}+\mathrm{L}$ each, $0.5 \%$ under $\mathrm{B}+$ and $0.5 \%$ had refused treatment. More than $70 \%$ of women being on the AZT $+3 \mathrm{TC}+\mathrm{NVP}$ and CTX regimen confirm that the latter is the preferential regime for the management of pregnant women in our environment [4] and approved by the study made in Lubumbashi that guarantees that the reduction of transmission is effective in a standard association used initially and in a greater way [10] [11].

For newborns, the male gender was more represented with more boys (52\%) 
than girls. Contrary to the study made in Lubumbashi by Mwemba et al. who made known that the female sex was the most dominant than boys (62.5\% against $37.5 \%$ ) [12]. At birth, 78 children (41\%) weighed between 2.01 and $3.00 \mathrm{~kg}$ weight, followed by $34 \%$ who weighed between 3.01 and $4.00 \mathrm{~kg}$, $2 \%$ weighing between 1.00 and $2.00 \mathrm{~kg}$ and only $3(2 \%)$ weighing more than $4.00 \mathrm{~kg}$. This confirms the report of the literature which stated that infant safety is to be monitored with a higher risk of low birth weight at delivery. In addition, 185 newborns (97\%) were put on treatment when 6 were not. Out of the 185, 49\% were on NVP syrup, $45 \%$ were on a combination of NVP syrup plus CTX and 6\% were only on CTX.

However, the United Nations program in charge of the AIDS (UNAIDS) stated in its progress report on the Global Plan that most of the priority countries still had a long way to go; Cameroon, Chad, Ivory Coast, the Democratic Republic of Congo and Ethiopia, which provided treatment to less than $10 \%$ of their Children Living with HIV (CLHIV) [3]. The treatment with NVP is so important because of its efficacy, simplicity and cost [13].

Ninety five percent (95\%) of children born to HIV-positive mothers were diagnosed HIV negative 9 months after birth by PCR and 2\% were not diagnosed as a result of their parents' refusal. This confirms that the acceptability of this diagnosis is often low. In accordance with the panel's recommendations that this test should be used in children under 18 months of age with perinatal exposure and at 14 to 21 days, 1 to 2 months to 4 to 6 months and 2 to 4 weeks after discontinuation of ARV prophylaxis. Bukongo NR, in his dissertation, stated that the guide to the management of HIV infection in children in the DRC recommends screening of HIV infection by PCR from 0 to 24 months and a second confirmation test by ELISA [14]. Out of the $98 \%$ of those diagnosed, 3 children (2\%) were diagnosed positive by PCR. This gives a mother-to-child transmission rate of $2 \%$ at 9 months of birth for the Kinshasa monitoring centers.

\section{Conclusion}

Despite the structural shortcomings encountered, the results obtained from this study indicate that the management of HIV-positive pregnant women in the centers of Kinshasa responds to the approach of PMTCT and that the monitoring of mother-child couples is done correctly. The vertical transmission rate is of $2 \%$.

\section{Conflict of Interest}

The authors declare that there is no conflict of interest.

\section{References}

[1] UNAIDS (2016) Global Report on the Global AIDS Epidemic.

[2] Ministère du Plan et Suivi de la Mise en œuvre de la Révolution de la Modernité et Ministère de la Santé Publique and République Démocratique du Congo (2014) Enquête Démographique et de Santé (EDS) 2013-2014: Rapport Annuel Préliminaire 
sur la Prévalence du VIH.

[3] United Nations Organization for the Fight against HIV/AIDS (UNAIDS) (2016) Progress Report at the Global Level.

[4] Programme National de Lutte contre le VIH/SIDA et les Infections Sexuellement Transmissible (PNLS) and Ministère de la Santé Publique and République Démocratique du Congo (RDC) (2016) Rapport Annueld' Activité 2015.

[5] World Health Organization (2012) Use of Antiretroviral to Treat Pregnant Women and Prevent HIV Infection in Infants.

[6] Programme National de Lutte contre le VIH/SIDA et les Infections Sexuellement Transmissible (PNLS) and Ministère de la Santé Publique and République Démocratique du Congo (RDC) (2014) Revue Nationale: Programme National de lutte contre le VIH et le SIDA innové en RDC; un accès au traitement antirétroviral simplifié et de qualité.

[7] (2012) Programme National Mutlisectoriel de Lutte contre le VIH/SIDA (PNMLS), République Démocratique du Congo. Rapport National.

[8] Bongenia, I.B., Ilombo, L.L., Botomwito, T.H., Bulanda, I.B., Kamangu, N.E., Lusakibanza, M. and Mesia, K.G. (2014) Fréquence du Suivi des Paramètres Biologiques des Patients sous Antirétroviraux à Kinshasa: Cas de l'Hôpital Provincial Général de Référence. Journal de Recherche Biomédicale, 1, 1-6.

[9] Bongenia, I.B., Bukongo, N.R., Kabasele, D.J.Y., Okonda, O.M., Chuga, D., Botomuito, T.H., Bulanda, I.B. and Kamangu, N.E. Prévalence des infections opportunistes chez les enfants infectés par le VIH de 0 à 12 ans à Kinshasa: Cas de l'hôpital pédiatrique de Kalembe Lembe.

[10] Kimbala, J., Mukuku, O., Tshibangu, C.K., Kapend, L., Numbi, O.L., Muteba, F., Mande, J., Ngoy, F.K., Lufwa, D., Matembo, P. and Kizonde, J. (2016) Prévention de la transmission du VIH de la mère à l'enfant à Lubumbashi en RDC: Résultats de 6 ans de pratique dans 5 maternités de référence. Médecine d Afrique Noire, 63, 111.

[11] Mwembo-Tambwe, N.A., Kalenga, P., Donnen, P., Chenge, M.F., Hulet, P., Dramaix, M. and Buekens, P. (2012) Delivery with Unknown HIV Serostatus in Lubumbashi: Proportion and Determinants. The Pan African Medical Journal, 12, 25-33.

[12] Kanteng, A.W., Assumani, N.A., ShongoYa, P.M., Yansenda, M.P., Mutoke, N.G., Ilunga, M.P. and Luboya, N.O. (2013) Prévalence et facteurs de risque liés à la transmission verticale du VIH. Cas du centre PTME des cliniques universitaires de Lubumbashi. Révue Médicales des Grands Lacs, 4, 12.

[13] Djadou, K.E., Ocloo, A., Dokounor, D., Agbodjan-Djoussou, O., Akapossa, A. and Atakouma, D.Y. (2006) Prise en charge des enfants nés des mères infectés par le VIH au Centre Hospitalier régional de Tsévié, Togo. Courte Note, \#3020.

[14] Ramazani, B.N. (2013) The Management of Opportunistic Infections in Children from 0 to 12 Years of Age Diagnosed HIV-Positive from 2007 to 2013, Born from HIV-Positive Mothers at Kalembelembe Pediatric Hospital City of Kinshasa. Dissertation, Technological University Bel Campus, Kinshasa. 